\title{
Identification of sequence polymorphisms in the D-loop region of mitochondrial DNA as valuable biomarkers for salivary gland tumors: an observational study
}

\author{
Hanspal Singh ${ }^{1^{*}}$, Somesh Kumar ${ }^{2}$, Aadithya B. Urs ${ }^{1}$ and Seema Kapoor ${ }^{2}$
}

\begin{abstract}
Background: Salivary gland tumor frequency in the head and neck region is quite less and mostly benign. However, pathogenesis is associated with oxidative stress in the mitochondria. Hence, we are aiming to identify single nucleotide polymorphisms (SNP)/single nucleotide variants (SNV) in the mitochondrial DNA D-loop region of salivary gland tumors (SGT). We analyzed 19 biopsied tissue (formalin-fixed paraffin-embedded) tumors, i.e., pleomorphic adenoma-5, mucoepidermoid carcinoma-6, adenoid cystic carcinoma-5, and polymorphous low-grade adenocarcinoma-3. This extracted DNA was amplified to visualize the entire D-loop region of the mitochondrial genome of SGT.

Results: The three hotspot mutation were noticed at 16,519 (thymine-cytosine) (number = 10), 73 (adenine-guanine) (number $=8$ ), and 195 (thymine-adenine) (number $=4$ ) in the D-loop in salivary gland tumors. We observed novel synonymous mutation in the 195 region of mitochondrial D-loop, which is a novel as per Mitomap (a human mitochondrial genomic database).

Conclusions: We hypothesized that the biological behavior of SGT is majorly dependent upon the stress level at mitochondria in the D-loop region. SNPs noted in mt-DNA should be noted as a pivotal biomarker for the progression or metastasis of SGT in individuals at risk.
\end{abstract}

Keywords: D-loop, Mitochondria, Variations, Salivary gland, Tumor

\section{Background}

In the head and neck region, salivary gland tumors comprise $3-6 \%$ only [1]. The pathogenesis of salivary gland tumors (SGT) has a direct link with the reactive oxygen species (ROS) produced during the oxidative phosphorylation process in the mitochondria [2]. As we know, mitochondrial DNA (mt-DNA) is almost $50 \%$ of the total genomic DNA of a cell and its gene products are important for cell survival in terms of ATP production. The double-stranded mt-DNA is circular in nature with 13

\footnotetext{
*Correspondence: drhans007@gmail.com

1 Department of Oral \& maxillofacial Pathology, Maulana Azad Institute

of Dental Sciences, BSZ Marg, New Delhi 110002, India

Full list of author information is available at the end of the article
}

essential polypeptides and a set of RNA for translation [3]. Any mutation may affect the basic activity of mitochondria. Hence, the vulnerability of mt-DNA is attributed to unguarded histones, a close approximation to oxidative phosphorylation sites, and failure in the DNA repair system $[4,5]$.

The protective mechanism of various antioxidants, i.e., glutathione peroxidase, catalase, superoxide dismutase (SOD), is required by mt-DNA for normal functioning. However, their effect is neutralized by excessive ROS produced during the growth of a tumor [6].

Numerous polymorphisms or variations are observed in the noncoding areas, i.e., the displacement loop (D-Loop) of mt-DNA [7]. 
So, we are aiming to identify single nucleotide polymorphisms (SNP)/single nucleotide variants (SNV) in the mitochondrial DNA D-loop region of salivary gland tumors (SGT).

\section{Methods}

\section{Sample collection}

This observational study included nineteen biopsied tissues (formalin-fixed paraffin-embedded, FFPE) of salivary gland tumors with informed written consent from the patients. Ethical approval for the study was granted by the institution.

Individuals with prior history of radiotherapy or chemotherapy were excluded from the study. These samples consisted of 19 cases of salivary gland tumors, i.e., pleomorphic adenoma (PA)-5, mucoepidermoid carcinoma (MEC)-6, adenoid cystic carcinoma (ACC)-5, and polymorphous low-grade adenocarcinoma (PLGA)-3.

Procedure: Total genomic DNA (including mitochondrial DNA) was isolated as per Singh $\mathrm{H}$ et al .[8]

The amplification of (D-Loop) of mt-DNA (1596416439) was performed using, i.e. 5'-AAAGTCTTTAAC TCCACC-3' (Forward) and 5'-GCACTCTTGTGCGGG ATATTG-3 (reverse) primers. The standardized PCR steps were followed i.e.

A) Initial denaturation for $5 \mathrm{~min}$ at $95^{\circ} \mathrm{C}$.

B) Thirty-five cycles of denaturation were performed at $95^{\circ} \mathrm{C}$ for $30 \mathrm{~s}$.

C) The annealing was performed at $59^{\circ} \mathrm{C}$ for $45 \mathrm{~s}$.

D) The elongation at $72^{\circ} \mathrm{C}$ for $45 \mathrm{~s}$ was performed followed by the final elongation of $7 \mathrm{~min}$.

The amplified DNA was further Sequenced and compared against a Mito-MAP [MITOMAP: A Human
Mitochondrial Genome Database; http://www.mitom ap.org]. The negative control used was nuclease-free water instead of DNA.

\section{Result}

The amplified PCR products showed sharp band formation in 18 cases with a faint band in the 19th case (Fig. 1).

After gene sequencing, only Seventeen out of the nineteen SGT cases showed sixty-one mitochondrial variations in the D-loop region (Tables 1 and 2; Figs. 2, 3 , and 4). The majority of reported SGTs are in the palate region (Table 3 ). No variations were detected in the 19th case (low to intermediate MEC) in the D-loop (non-coding) region. Similarly, intermediate grade MEC showed no variation. Only synonymous variations were observed in our cases with no amino acid changes.

Gas chromatography preceding sequencing was performed. So, we noticed 16519 and 73 were the hotspot for the maximum silent mutation in present SGT groups.

The three hotspot mutation were noticed in 16519 (T-C) $(N=10), 73(\mathrm{~A}-\mathrm{G})(N=8)$, and $195(\mathrm{~T}-\mathrm{A})(N=4)$ in the D-loop (Table 1; Fig.1).

We also observed novel synonymous variation at the 195th position of the mitochondrial D-loop region, which was never reported as per Mitomap (A human mitochondrial genomic database).

It showed female predilection with 13 females and 6 males between the ages of 20 and 70 years. Seven patients were above 50 years of age and the remaining 12 patients were below 50 years of age

The insertion of cytosine $\{C\}$ at 302 region was seen among 3 cases, i.e., PA, MEC, and PLGA (Table 1).

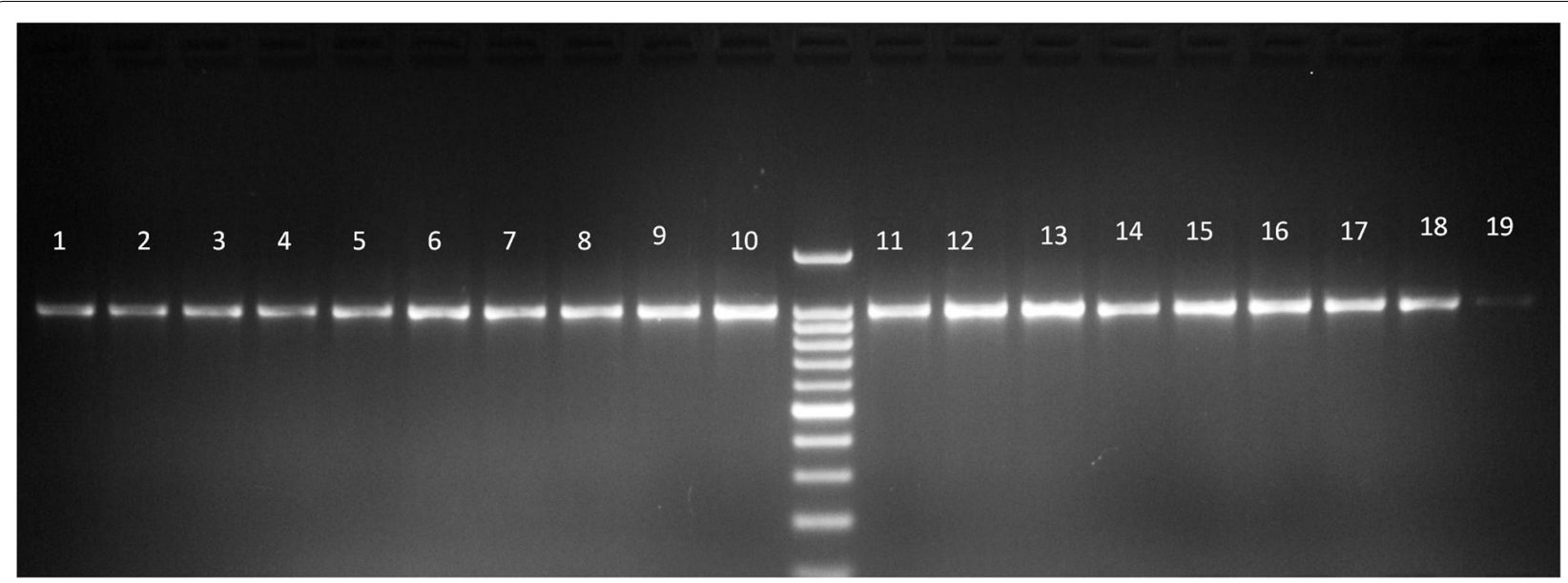

Fig. 1 Gel electrophoresis showed band formation at 831 bp 
Table 1 Common D-loop variations among the groups

\begin{tabular}{|c|c|c|c|c|c|c|c|}
\hline Locus & Base change & Region & $\mathrm{PA}(N=5)$ & MEC $(N=6)$ & $\mathrm{ACC}(N=5)$ & $\operatorname{PLGA}(N=3)$ & Total \\
\hline 16519 & $\mathrm{~T}-\mathrm{C}$ & HV I & $4(80 \%)$ & $2(33.3 \%)$ & $2(33.3 \%)$ & $2(66.7 \%)$ & 10 \\
\hline 73 & $A-G$ & HV II & $3(60 \%)$ & $1(16.7 \%)$ & $2(40 \%)$ & $2(66.7 \%)$ & 8 \\
\hline 195 & T-A & HV II & $2(40 \%)$ & $1(16.7 \%)$ & $0(0 \%)$ & $1(33.3 \%)$ & 4 \\
\hline 152 & $\mathrm{~T}-\mathrm{C}$ & HV II & $0(0 \%)$ & $0(0 \%)$ & $2(40 \%)$ & 1 (33.3\%) & 3 \\
\hline 206 & $\mathrm{~T}-\mathrm{C}$ & HV II & $1(20 \%)$ & $1(16.7 \%)$ & $1(20 \%)$ & $0(0 \%)$ & 3 \\
\hline 302 & C INS & HV II & $1(20 \%)$ & 1 (16.7\%) & $0(0 \%)$ & 1 (33.3\%) & 3 \\
\hline 489 & $\mathrm{~T}-\mathrm{C}$ & HV II & 2 (40\%) & $0(0 \%)$ & $1(20 \%)$ & $0(0 \%)$ & 3 \\
\hline 16319 & G-A & HV I & $1(20 \%)$ & $0(0 \%)$ & $2(40 \%)$ & $0(0 \%)$ & 3 \\
\hline 194 & C-T & HV II & $1(20 \%)$ & $1(16.7 \%)$ & $0(0 \%)$ & $0(0 \%)$ & 2 \\
\hline 209 & G-A & HV II & $0(0 \%) 0$ & $0(0 \%)$ & $1(20 \%)$ & 1 (33.3\%) & 2 \\
\hline 217 & $\mathrm{~T}-\mathrm{C}$ & HV II & $1(20 \%)$ & $0(0 \%)$ & $1(20 \%)$ & $0(0 \%)$ & 2 \\
\hline $514-515$ & CA deletion & HV III & $1(20 \%)$ & $0(0 \%)$ & $1(20 \%)$ & $0(0 \%)$ & 2 \\
\hline 16302 & A-G & HV I & $1(20 \%)$ & $0(0 \%)$ & $1(20 \%)$ & $0(0 \%)$ & 2 \\
\hline 16362 & $\mathrm{~T}-\mathrm{C}$ & HV 1 & $0(0 \%)$ & $0(0 \%)$ & $1(20 \%)$ & 1 (33.3\%) & 2 \\
\hline
\end{tabular}

PA pleomorphic adenoma, MEC mucoepidermoid carcinoma, ACC adenoid cystic carcinoma, PLGA polymorphous low-grade adenocarcinoma, HV hypervariable

Table 2 Uncommon D-loop variations among the groups

\begin{tabular}{|c|c|c|c|c|c|c|c|}
\hline Locus & Base change & Region & $\mathrm{PA}(N=5)$ & $\operatorname{MEC}(N=6)$ & $\mathrm{ACC}(N=5)$ & $\operatorname{PLGA}(N=3)$ & Total \\
\hline 35 & G-A & MT-CR & $0(0 \%)$ & $0(0 \%)$ & $1(100 \%)$ & $0(0 \%)$ & 1 \\
\hline 36 & $G-A$ & $M T-C R$ & $0(0 \%)$ & $0(0 \%)$ & $1(100 \%)$ & $0(0 \%)$ & 1 \\
\hline 143 & $G-A$ & HV-II & $1(100 \%)$ & $0(0 \%)$ & $0(0 \%)$ & $0(0 \%)$ & 1 \\
\hline 200 & $A-G$ & HV-II & $1(100 \%)$ & $0(0 \%)$ & $0(0 \%)$ & $0(0 \%)$ & 1 \\
\hline 235 & $A-G$ & $H V-\|$ & $1(100 \%)$ & $0(0 \%)$ & $0(0 \%)$ & $0(0 \%)$ & 1 \\
\hline 482 & $\mathrm{~T}-\mathrm{C}$ & $H V-\|$ & $1(100 \%)$ & $0(0 \%)$ & $0(0 \%)$ & $0(0 \%)$ & 1 \\
\hline 16274 & G-A & HV-I & $0(0 \%)$ & $0(0 \%)$ & $1(100 \%)$ & $0(0 \%)$ & 1 \\
\hline 16278 & $C-T$ & HV-I & $0(0 \%)$ & $1(100 \%)$ & $0(0 \%)$ & $0(0 \%)$ & 1 \\
\hline 16290 & $C-T$ & HV-I & $0(0 \%)$ & $0(0 \%)$ & $1(100 \%)$ & $0(0 \%)$ & 1 \\
\hline 16292 & $C-T$ & HV-I & $0(0 \%)$ & $0(0 \%)$ & $1(100 \%)$ & $0(0 \%)$ & 1 \\
\hline 16295 & $C-T$ & $H V-I$ & $1(100 \%)$ & $0(0 \%)$ & $0(0 \%)$ & $0(0 \%)$ & 1 \\
\hline 16456 & $G-A$ & Non coding region & $0(0 \%)$ & $0(0 \%)$ & $1(100 \%)$ & $0(0 \%)$ & 1 \\
\hline
\end{tabular}

PA pleomorphic adenoma, MEC mucoepidermoid carcinoma, ACC adenoid cystic carcinoma, PLGA polymorphous low-grade adenocarcinoma, $H V$ hypervariable

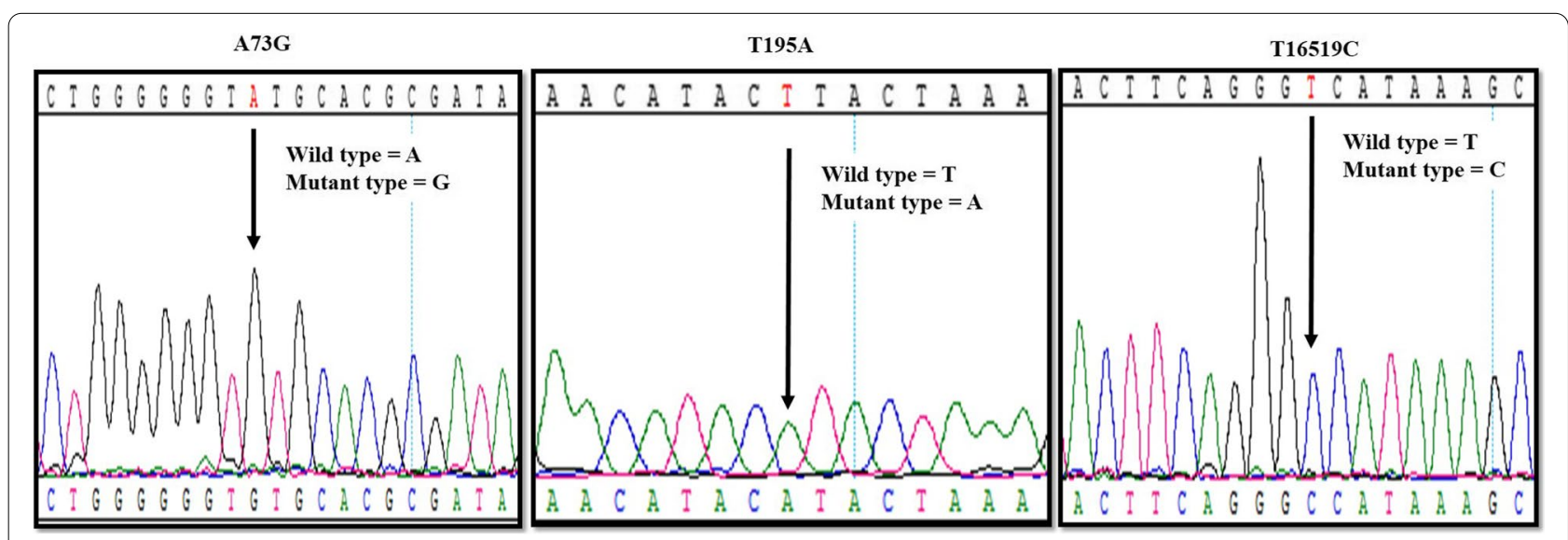

Fig. 2 Chromatogram showing a synonymous mutation in D-loop region of salivary gland tumor at 73, 195, and 16519 base position 

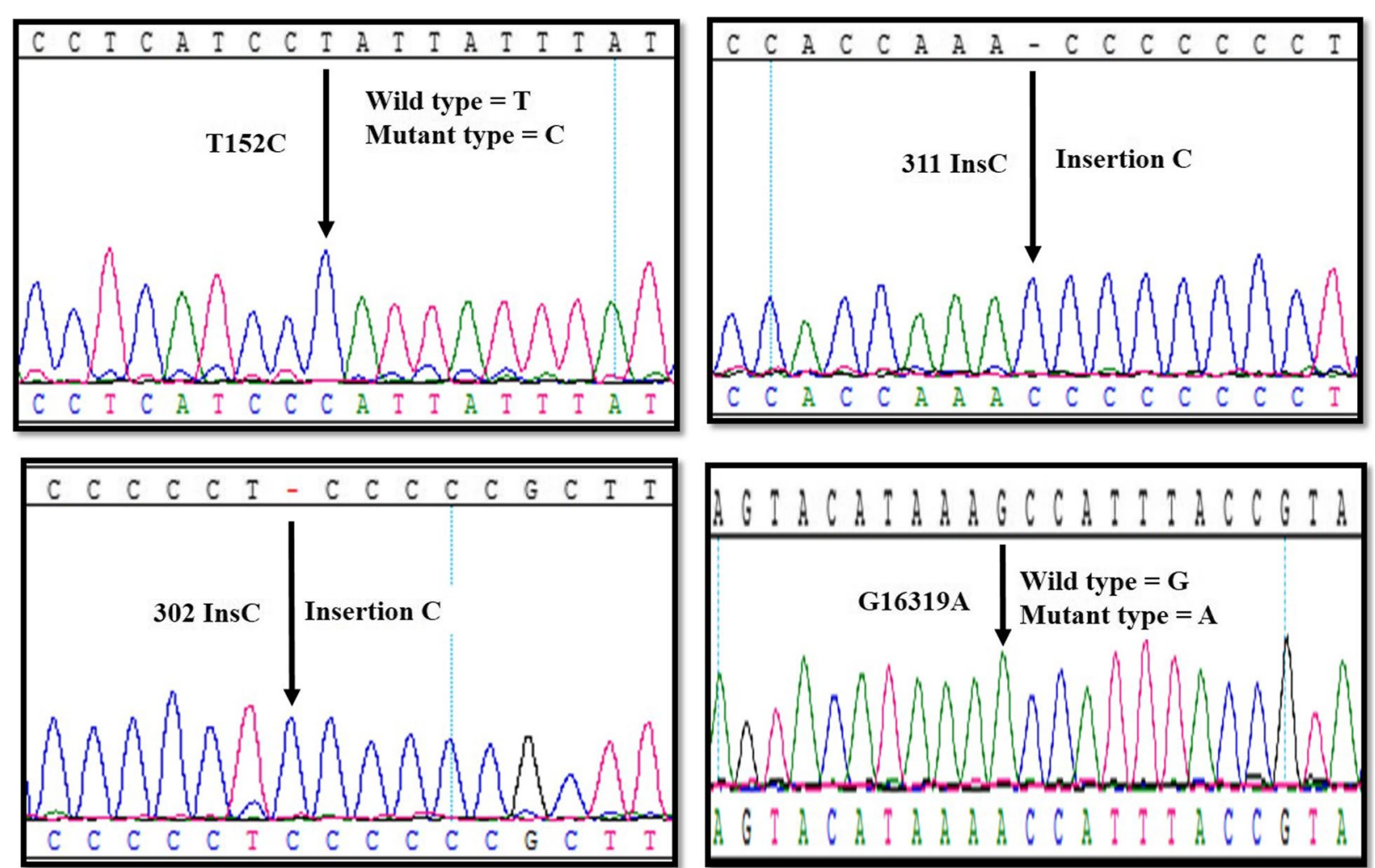

Fig. 3 Chromatogram showing synonymous variation at 152, 311,302, and 16319 base position

\section{Discussion}

The D-loop region is the replication point for the mtDNA [5]. The hypervariable regions and vulnerability to somatic variations are attributed due to the distinctive triple-stranded DNA structure, which in turn responsible to produce excessive ROS [6].

Our understanding regarding the association of variations found in the D-Loop region of mt-DNA at hypervariable $(\mathrm{HV})$ regions of SGT is minimal due to the dearth of documentations. So this study was designed to investigate the incidence and distribution of mitochondrial mutation in SGT, which might further facilitate in identification of a novel therapeutic approach.

Also, the SNVs i.e. 73A/G was observed in the current study including other cancers like pancreas [9], breast [10], prostate [11], esophageal squamous cell [12], and lung [13], which suggested a vital role in the pathogenesis and biological behavior of any tumors. Hence, might modulate the risk outcome of the tumor.

The hypervariable (HV) segments of the D-loop have the maximum penetrance of cancer risk-associated SNP/ SNV sites, with nucleotide 16519 (HV-I), 73 (HV-II), and 195 (HV-II) being the common variations in our study.
Another common polymorphic region is at 302 region, which falls in the D310 region. Also, the D310 region appeared to be a hot spot region in many other cancers $[13,14]$. Other common and uncommon SNP and Single nucleotide variants (SNV) sites are also mentioned in Tables 1 and 2 .

The gene bank frequency of T16519C, A73G, and T195C SNPs is 55371, 66719, and 15783 in number, respectively, suggesting their role in various tumorigenesis.

Mithani S K et al attempted to show the frequent mitochondrial genetic alteration in the D-loop of ACC with a high incidence of amino acid changes, suggested the association with the carcinogenesis/progression. Despite 50\% SNPs (1-13 mutation/tumor) in D-loop hypervariable regions, still, their direct role was not clear. In the present study, we noted 0-7 mutation/tumor with similar SNP (T16519C) in the majority of our ACC cases with no alteration in final amino acid [15]. However, it might have affected the clinical and biological behavior of SGTs in present cases.

The male ratio was $50 \%$, in comparison to females in Mithani S K et al's study of ACC, whereas it was 31\% in 


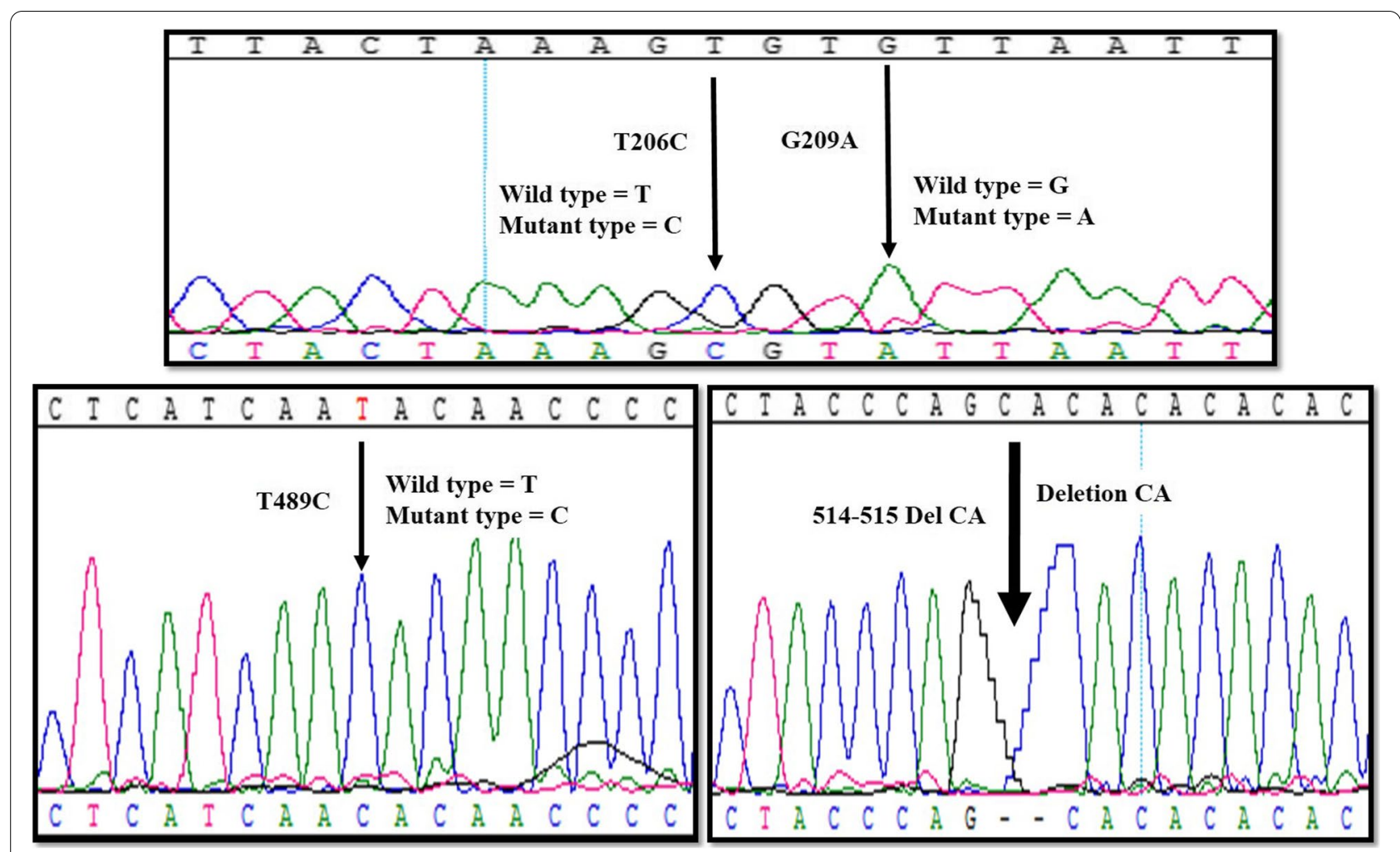

Fig. 4 Chromatogram showing synonymous variation in D-loop region at 206, 209, 489, and $513-514$ base position

Table 3 Depicting the tumor and their locations

\begin{tabular}{lll}
\hline Case no. & Tumor & Location \\
\hline 1 & Intermediate-grade MEC & Right hard palate \\
2 & ACC & Upper lip \\
3 & PA & Right parotid gland \\
4 & PA & Left parotid gland \\
5 & Low-grade MEC & Left palate \\
6 & ACC & HP-SP junction \\
7 & PA & parotid gland \\
8 & PLGA & Left half of palate \\
9 & Low-grade MEC & Right hard palate \\
10 & PLGA & Left palate \\
11 & PA & Left parotid \\
12 & ACC & Hard palate \\
13 & PLGA & Right side of the palate \\
14 & PA with mucinus metaplasia & Parotid gland \\
15 & Low-grade MEC & Left body of ramus \\
16 & Low intermediate MEC & Hard palate \\
17 & ACC & Right hard palate \\
18 & Low-grade MEC & Hard palate \\
19 & PA & Parotid gland \\
\hline
\end{tabular}

ACC adenoid cystic carcinoma, MEC mucoepidermoid carcinoma, HP-SP hard palate-soft palate, $P A$ pleomorphic adenoma, PLGA polymorphous low-grade adenocarcinoma the present study. It suggested females are more susceptible in comparison to males in our study [15].

As per our observation, the patient below the age of 40 years is under the risk category for the progression of developing SGT. While in Mithani S K et al.s study, it was over 40 years.

As per Sanchez-Cespedes et al's. observations, head and neck region tumors showed maximum variations in the D- loop region of mt-DNA in many tumors. It has also been postulated that a slight change at any given steps of cellular division might lead to the random selection and assimilation in the genome, which manifest in the form of a tumor [16]. Capone et al's study on oncocytic neoplasms showed only one case of mt-DNA, C tract alteration among 21 cases, suggesting heteroplasmy character. So, further investigations need to be performed to evaluate the mt-DNA heteroplasmy depending upon the localization of the mitochondrial cells in the association with oncocytic neoplasms of the parotid gland [17].

\section{Conclusions}

We hypothesized that the biological behavior of SGT is majorly dependent upon the stress level at mitochondria in the D-loop region, which results in progression. 
SNPs noted in mt-DNA should be noted as a pivotal biomarker for the progression or metastasis of SGT in individuals at risk. We also need to revalidate all these SNPs in more cases to further add on the pathogenesis aspects.

\section{Abbreviations}

mtDNA: Mitochondrial DNA; SGT: Salivary gland tumors; SNPs: Single nucleotide polymorphisms; SNVs: Single nucleotide variants; C-tract: Cytosine tract; HV: Hypervariable; ROS: Reactive oxygen species.

\section{Acknowledgements}

We would like to acknowledge Atul Bhat for his technical help and general support.

\section{Authors' contributions}

HS was a major contributor in designing the study, collecting data and interpretation, and drafting regarding polymorphism in mitochondrial D-loop region. SoK contributed to getting data and bioinformatics. AB contributed to the drafting, and study was done under the general guidance of SK throughout the work. All authors read and approved the submitted final version.

\section{Funding}

No funding was provided for this study.

\section{Availability of data and materials}

The datasets used and/or analyzed during the current study are available by the corresponding author and ready to be shared upon reasonable request.

\section{Declarations}

\section{Ethics approval and consent to participate}

All procedures performed in this study were in accordance with the ethical standards of the research committee of Maulana Azad Institute of Dental sciences. Ethical approval was granted by the board.

Informed written consent to participate in the study was provided by all participants.

\section{Consent for publication}

All presentations of case reports have written consent to publish by patients.

\section{Competing interests}

The authors declare that they have no competing interests.

\section{Author details}

${ }^{1}$ Department of Oral \& maxillofacial Pathology, Maulana Azad Institute of Dental Sciences, BSZ Marg, New Delhi 110002, India. ${ }^{2}$ Dept of Pediatric and Genetic Laboratory, Lok Nayak Hospital, New Delhi 110002, India.

Received: 7 May 2021 Accepted: 7 January 2022

Published online: 08 February 2022

\section{References}

1. Stryjewska-Makuch G, Kolebacz B, Janik MA, Wolnik A (2017) Increase in the incidence of parotid gland tumors in the years 2005-2014. Otolaryngol Polska. 71(2):29-34

2. Morry J, Ngamcherdtrakul W, Yantasee W (2017) Oxidative stress in cancer and fibrosis: opportunity for therapeutic intervention with antioxidant compounds, enzymes, and nanoparticles. Redox Biol 11:240-253

3. Anderson S, Bankier AT, Barrell BG, de Bruijn MH, Coulson AR, Drouin J, Eperon IC et al (1981) Sequence and organization of the human mitochondrial genome. Nature. 290:457-465

4. Chatterjee A, Mambo E, Sidransky D (2006) Mitochondrial DNA mutations in human cancer. Oncogene. 25:4663-4674
5. Fliss MS, Usadel H, Caballero OL, Wu L, Buta MR, Eleff SM, Jen J, Sidransky D (2000) Facile detection of mitochondrial DNA mutations in tumors and bodily fluids. Science. 287:2017-2019

6. Cadet J, Berger M, Douki T, Ravanat JL (1997) Oxidative damage to DNA formation, measurement, and biological significance. Rev Physiol Biochem Pharmacol. 131:1-87

7. Parsons TJ, Muniec DS, Sullivan K, Woodyatt N, Alliston-Greiner R, Wilson MR, Berry DL, Holland KA, Weedn VW, Gill P, Holland M, M, (1997) A high observed substitution rate in the human mitochondrial DNA control region. Nat. Genet. 15:363-368

8. Singh H, Narayan B, Urs AB, Kumar Polipalli S, Kumar S (2020) A novel approach for extracting DNA from formalin-fixed paraffin-embedded tissue using microwave. Med J Armed Forces India. 76(3):307-311

9. Navaglia F, Basso D, Fogar P, Sperti C, Greco E, Zambon CF, Stranges A et al (2006) Mitochondrial DNA D-loop in pancreatic cancer: somatic mutations are epiphenomena while the germline 16,519T variant worsens metabolism and outcome. Am J Clin Pathol 2006(126):593-601

10. Bai RK, Leal SM, Covarrubias D, Liu A, Wong LJ (2007) Mitochondrial genetic background modifies breast cancer risk. Cancer Res. 67:4687-4694

11. Wang L, McDonnell SK, Hebbring SJ, Cunningham JM, St Sauver J, Cerhan JR, Isaya G, Schaid DJ, Thibodeau SN (2008) Polymorphisms in mitochondrial genes and prostate cancer risk. Cancer Epidemiol Biomarkers Prev. 17(12):3558-3566

12. Zhang R, Wang R, Zhang F, Wu C, Fan H, Li Y, Wang C, Guo Z (2010) Single nucleotide polymorphisms in the mitochondrial displacement loop and outcome of esophageal squamous cell carcinoma. J Exp Clin Cancer Res. 29(1):155

13. Ha PK, Tong BC, Westra WH, Sanchez-Cespedes M, Parrella P, Zahurak M, Sidransky D et al (2002) Mitochondrial C-tract alteration in premalignant lesions of the head and neck: a marker for progression and clonal proliferation. Clin Cancer Res. 8:2260-2265

14. He Y, Wu J, Dressman DC, lacobuzio-Donahue C, Markowitz SD, Velculescu VE et al (2010) Heteroplasmic mitochondrial DNA mutations in normal and tumor cells. Nature. 464:610-614

15. Mithani SK, Shao C, Tan M, Smith IM, Califano JA et al (2009) Mitochondrial mutations in adenoid cystic carcinoma of the salivary glands. PLoS One 4(12):e8493

16. Coller HA, Khrapko K, Bodyak ND et al (2001) High frequency of homoplasmic mitochondrial DNA mutations in human tumors can be explained without selection. Nat Genet. 28:147-150

17. Capone RB, Ha PK, Westra WH, Pilkington TM, Sciubba JJ, Koch WM, Cummings CW (2002) Oncocytic neoplasms of the parotid gland: a 16-year institutional review. Otolaryngol Head Neck Surg 126(6):657-662

18. Sanchez-Cespedes M, Parrella P, Nomoto S et al (2001) Identification of a mononucleotide repeat as a major target for mitochondrial DNA alterations in human tumors. Cancer Res. 61:7015-7019

\section{Publisher's Note}

Springer Nature remains neutral with regard to jurisdictional claims in published maps and institutional affiliations.

\section{Submit your manuscript to a SpringerOpen ${ }^{\circ}$ journal and benefit from:}

- Convenient online submission

- Rigorous peer review

- Open access: articles freely available online

- High visibility within the field

- Retaining the copyright to your article

Submit your next manuscript at $\boldsymbol{\nabla}$ springeropen.com 